\title{
Community development and engagement with local governance in South Africa
}

\author{
Imraan Buccus, David Hemson, Janine Hicks and \\ Laurence Piper
}

Abstract The issue of public participation is receiving increasing attention in South Africa, from both government and civil society sectors. We are witnessing acknowledgement from a wide range of public institutions that insufficient consideration has been paid to public participation, and that existing policy frameworks, institutional mechanisms and programme interventions are failing to comply with government's constitutional and statutory obligations in this regard. This article examines actual practice in one key 'invited space': the policy and legislative framework for public participation in municipal processes. The article also highlights community experiences of attempting to engage with municipalities in development planning and policy processes, and their aspirations and expectations in this regard. We conclude with a set of recommendations on how participatory development at the local level can be transformed to ensure that municipal planning and programme implementation processes are truly accessible, participatory and empowering for local communities.

\section{Introduction}

The issue of public participation is receiving increasing attention in South Africa, from both government and civil society sectors. We are witnessing acknowledgement from a wide range of public institutions that insufficient consideration has been paid to public participation, and that existing policy frameworks, institutional mechanisms and programme interventions are failing to comply with government's constitutional and statutory obligations in this regard. Constitutional Court rulings such as the Grootboom ruling (Lahiff and Rugege, 2002) have reinforced this, with proposed 
legislation being returned to Parliament to provide for sufficient engagement with civil society and other affected stakeholders.

This has significant implications for Parliament and provincial legislatures, which are in the process of developing a policy framework and something approaching a standardized approach to public participation. Likewise, municipalities and several provincial governments (including KwaZulu-Natal (KZN) and Western Cape) have implemented a process to develop guidelines and programmes to ensure that public participation obligations are adequately met. The question is whether this provides substantial opportunities for public engagement or is merely a formality. This is particularly important for local government, as the formal requirements to consult the public, Cornwall's (2004) 'invited spaces' are more developed here than in provincial or national spheres. Despite a legacy of struggle for public participation reflecting mass resistance to apartheid, public servants are often unenthusiastic about the formalities, and communities unsure about the substance.

Civil society organizations are identifying the need to strengthen their advocacy interventions and revisit their approach to government, and to ensure their engagement with government processes has meaningful impact. This has traditionally taken the form of Cornwall's 'claimed spaces' (2004) - demonstrations and protests over service delivery and consultation. The debate in civil society is now whether the formal processes will lead to co-optation and conflict within civil society rather than social progress, or whether participation leads to any significant change at all.

Social movement actors are debating the value of government's 'invited spaces' to facilitate public participation and how to use the muscle of mass mobilization and protest to strengthen their hand in an otherwise unequal power relationship within that highly contested arena that characterizes policy-making. Hence, the issue of creating new 'invented spaces' remains on the agenda. Civil society stakeholders are seeking strategies, which will not only avoid co-optation, but strengthen the democratic practices and genuine reforms so eagerly anticipated by the poor.

This article examines actual practice in one key 'invited space': the policy and legislative framework for public participation in municipal processes. Participation in development in South Africa flows along lines which differ in important aspects from other developing countries; community development is cast within the framework of rights and entitlements, and by law the municipality is required to operate as the 'efficient, frontline development agency' for socioeconomic upliftment (Preamble, Municipal Systems Act, No. 32 of 2000).

Participation is thus framed largely within the context of local government and expectations of service delivery from government. There 
is legislative provision for consultation, ward committees (elected community representative structures chaired by the ward councillor), citizen voice in planning, and in assessment of the performance of municipalities, a set of entitlements which appear to go beyond that of other developing countries. The experience is, however, mixed and uneven.

Drawing on findings of a joint research initiative between the Centre for Public Participation, the Human Sciences Research Council, and the University of KwaZulu-Natal into public participation in local governance and community development, we assess the current mechanisms and systems implemented by municipalities in $\mathrm{KZN}$, and some emerging models on which to build to enable effective and meaningful citizen engagement.

The article also highlights community experiences of attempting to engage with municipalities in development planning and policy processes, and their aspirations and expectations in this regard. We conclude with a set of recommendations on how participatory development at the local level can be transformed to ensure that municipal planning and programme implementation processes are truly accessible, participatory and empowering for local communities.

\section{Policy and legislative framework for participation}

South Africa is multi-party, representative democracy, under a constitution which is sovereign and which entrenches human rights. In addition, state power is mostly centralized in the national sphere, with only limited power devolved to provinces and local municipalities. Despite being a representative democratic system, the South African Constitution and some legislation complement the power of elected politicians with forms of public participation. In the national and provincial spheres, this takes the form of public consultation by legislatures. In the municipal sphere, there are specific requirements for public participation.

In addition, the public service has committed itself to being more responsive, accountable and transparent in implementing government policy. On the whole though, public participation is limited to forms of consultation, usually around needs, rather than any real empowerment in political decision-making or implementation and surveys record low levels of participation (Hemson, 2007). Despite this, given a history of unresponsive bureaucracy, forms of participation could work as a check on all levels of the state's implementation of housing and other services. Given a political system which is strongly dominated by a single party, such participation could operate to achieve greater accountability than that of the formal political processes. 
The requirement that national and provincial legislatures consult is reflected in Section 59(1) of the 2006 Constitution which states that 'The National Assembly must...facilitate public involvement in the legislative and other processes of the Assembly and its committees'. Section 118 makes similar requirements for the provinces. Notably, the Constitution makes it clear that decision-making power resides with parliament alone, reflecting the reality that public participation is limited to informing the deliberations of parliament.

Significantly, the obligations on the local sphere to consult are more developed. Hence Section 152(1) of the Constitution states that 'local government must encourage the involvement of communities and community organisations in the matters of local government.' This implies going a little beyond just consulting communities as an aid to deliberation. In this regard, the Municipal Systems Act, 2000, section 16, obliges municipalities to 'develop a culture of municipal governance that complements formal representative government with a system of participatory governance, and must for this purpose (a) encourage, and create conditions for, the local community to participate in the affairs of the municipality, including in-(i) integrated development planning; (ii) the performance management system; (iii) performance, (iv) the budget (v) and strategic decisions relating to services. If this were vigorously employed, this could lead to highly engaged Q1 communities such as evident in Porto Allegre and other situations where democracy and planning are closely linked.

In addition to requiring that local councils consult communities on key municipal processes, the Municipal Structures Act of 1998 establishes ward committees. Consisting of ten people and chaired by the ward councillor, ward committees are intended to act as the main means of communication between the council and local communities. Notably, however, as with the national and provincial spheres, legislation makes it clear that decisionmaking powers rest with council alone, and that public participation around key council processes or through ward committees really means community consultation to aid the deliberations of municipal councils.

Lastly, the civil service is bound the policy of Batho Pele ('People First') (1997) to 'get public servants to be service orientated, to strive for excellence in service delivery and to commit to continuous service delivery improvement'. In the words of the policy, 'it is a simple and transparent mechanism, which allows citizens to hold public servants accountable for the level of services they deliver'. This provides another, less structured but nevertheless important normative resource for civil society and local communities to press for more responsive policy implementation. Unfortunately, the eight Batho Pele principles do not apply to the municipal sphere where public participation is prioritized, although this is now to be changed. 
Nevertheless, to the extent that government has created 'invited spaces' for public consultation, to date these has been largely ceremonial and without bearing on the urgent issues of the moment. This raises the question of whether participation leads to incorporation without redress, as some argue, or whether there is a lag in the official policy of 'deepening democracy'.

\section{Current mechanisms and systems for citizen engagement}

The research project looked at a representative sample of four of the nine local government district municipalities in KZN: Mgungundlovu, Ilembe, Sisonke and eThekwini district councils. This particular aspect of the research was an attempt to gain a 'top-down' understanding of public participation. In other words, it was an attempt to assess existing attitudes, approaches, systems and structures, programmes and resources for public participation at the district council level in KZN.

In post apartheid South Africa, participation has to have an element of redress for the historical exclusion of the majority at the local level. However, while the involvement and engagement of ordinary people in the design, planning and evaluation of development programmes, and plans at the local level should be an integral part of democratic practice in South Africa, there are still huge gaps in terms of how this process is being facilitated. The fact that the entire arena of participation in government processes is fairly new may account, somewhat, for the deficiencies in the way local government practitioners facilitate participation.

The processes are complex. While there is expressed political will for public participation, this is not fully developed nor implemented in a meaningful way. The popular mass meetings or izimbizo ${ }^{1}$ and 'road shows' are sometimes seen as exercises for the endorsement of pre-designed programmes. Although izimbizo are often addressed by high-level politicians and often draw crowds of thousands, they do not necessarily lead to meaningful deliberation of development challenges and policy options, nor the resolution of long-standing grievances. The problem is often of effective linkage between such mass meetings and the planning and budgetary processes of government. While some districts reflected good publicity and 205 clear agendas for izimbizo, only in Ilembe were minutes or official notes taken, with evidence of follow-ups by officials on issues raised.

The following overview sets out details of attitudes and perceptions towards public participation and current participatory mechanisms and 
resources for these in place in municipalities, according to stakeholders interviewed.

\section{Attitudes and perceptions}

Across the municipalities consulted, there appeared to be a fair degree of commitment by local government stakeholders to public participation. The question is, however, whether this leads to impact on municipal decisionmaking. Perhaps the key positive finding on interviewing municipal councillors and officials is that they all affirmed the importance of public participation in local governance. They felt that public participation required the involvement of communities, political parties and other stakeholders, and was important to ensure accountability and transparency. A reason often given was the exclusionary development planning process at the local level under the apartheid era and a strong desire to avoid repeating this practice.

The overwhelming impression created, however, was that municipalities realize that public participation is constitutionally and legislatively provided for, and therefore must be undertaken: generally after high-level planning has been undertaken and budgets set. Generally, there were no clear indicators of a commitment to meaningful and penetrating participation. The pervading attitude appearing among officials was that they know what people want and therefore participation is not necessary. As one top official commented, 'We know what people's needs are, and what they will be for the next 100 years, only the rank order will change'. This approach seems to be a technocratic approach to development, thus negating the notion that local knowledge and open democratic processes assist in shaping policies and implementing services. Social surveys, such as quality of life surveys, were seen as better mechanisms to judge issues and to measure change.

Councillors and officials demonstrated awareness of constitutional and legislative requirements for public participation, and most were able to identify specific municipal functions where public participation should be provided for, namely the Integrated Development Planning (IDP) and budget processes, and performance management. Most were able to identify current mechanisms to facilitate participation in these processes, such as ward committees; ward councillors, community-based planning; community development workers (CDW); and izimbizo and other forms of public hearings and meetings. These mechanisms range from those which are easily accessible to 'invitation only' consultations such as business breakfasts.

\section{Existing mechanisms for public participation}

\section{IDP and the budget process}

Research data reveals that there is no standard approach to the IDP process, with municipalities developing varying approaches to development 
planning and drawing community stakeholders into these processes. Importantly, all municipalities report adherence to the requirement of consultation in planning, although the substance of that consultation can be questionable. In this regard, all municipalities claimed to have had at least some izimbizo on the IDP and budget at both district and local levels. While draft documents are often not accessible in some municipalities, the Sisonke municipality reports that copies of municipal IDPs are advertised in the newspapers, taken to tribunal courts, libraries, police stations and local municipalities for community members to access.

The Ethekwini municipality does not convene IDP forums, but rather its own 'Big Mama workshops', which included many sectoral stakeholders, such as business forums, unions and civil society organizations, as well as geographically based representatives. These workshops constitute consultative forums on the city's development plan and also on the budget process.

In other municipalities, IDP participatory processes take the form of ward meetings. These meetings are advertised using loud hailers, among other 'marketing' initiatives. Libraries have suggestion boxes with feedback being received mostly from middle-class communities who seem to value and respond to such a facility being made available.

\section{Performance Management}

275 Most municipalities indicate that there is confusion when it comes to issues of performance management, and agree that there is a need to re-engineer the system so that it will be taken seriously and respected. Generally, performance is assessed only at the broadest of levels, for example, the eThekwini practice of using the Big Mama workshops as a forum to gather an indication of whether people are happy with the municipality's performance. The performance and service delivery of departments and senior officials according to performance criteria is, however, not subject to public scrutiny. Performance management is treated as a technical and legal issue, ultimately overseen by the auditor general.

\section{Ward committees}

Ward committees are set out in legislation and policy as the institution to link communities and local politicians. Chaired by ward councillors, they are the foundation stones for community participation in development processes and municipal decision-making, but despite their promise, ward committees often function poorly.

Overall, there appears to be no common understanding of how ward committees can feed into municipal development planning and decisionmaking. There are also no resources made available to the functioning of 
ward committees, nor any stipend made available or travel or administration costs covered for ward committee members, many of whom lack meaningful understanding of municipal processes and how best to assert community needs into the development planning process. In one municipality, it was further mentioned that there are no ward committees for the district municipality, and no policy guidelines on how the district should utilize ward committees at the local municipality level.

At the time of gathering this data, there were no functional ward committees in the Sisonke District or the eThekwini municipality, but they were in the process of being elected. Elections are sometimes marred by controversy; at times councillors are accused of packing in their favourites, and ward committees are perceived as mere extensions of local party structures, while others are marked by fierce contest for these positions. Ward councillors at times complain that they do not have the information or power to champion key ward issues in Council, calling into question the value of the entire system of ward committees.

\section{Community Development Workers}

CDWs have been launched nationally as agents for change at the local level, but municipalities agree that this is a poorly defined and understood territory. CDWs are employees of provincial departments of Local Government and Traditional Affairs, with one CDW deployed to each municipal ward. CDWs may possibly be integrated as officials in ward committees, whose work they are supposed to strengthen.

While, in some municipalities, the CDWs work reasonably well with local structures, elsewhere there is no clarity about their tasks and to whom they should report. In one district, reports from individual CDWs are not received, and their role in supporting the delivery of essential services was unclear. Most saw it important that CDWs have some relation with ward committees, perhaps even acting as their secretariat. Sisonke officials pointed to the fact that CDWs assist communities in expressing their needs and provide direction to the availability of services. In this district, CDWs are mainly concerned with the dissemination of information required by communities.

\section{Public hearings}

According to legislation, public hearings should be convened on the passing of municipal by-laws. This generally appears as an 'elite' form of participation, with advertising for this taking the form of print and electronic media. In eThekwini, public hearings take place for the budgeting process. However, the timing is problematic and the process usually entails the presentation of a highly developed and inflexible plan rather than open consultation and redress. 


\section{Structure, resources and staffing supporting participation}

In many municipalities, officials argue that they have not yet had the time or resources to develop public participation. Most municipalities currently have no staff members designated to drive public participation programmes, even although these are provided for in municipal organograms. There is, however, no policy to guide municipalities in terms of the number of staff they should employ and what their duties should entail. Some municipalities currently utilize the services of existing staff members to fulfil this function, especially from Planning and Implementation Management units.

Most municipalities complained of budget constraints and scarcity of resources to undertake public participation, although the National government has apparently made an undertaking to municipalities to make funds available. Ethekwini Municipality is the only municipality with a dedicated community participation unit with a structured staff complement, although this municipality is not spoken of as a model of responsiveness.

\section{Community experiences of engagement}

While community perceptions of municipalities' attempts to engage them in development planning and municipal decision-making processes have generally been negative, with respondents feeling that, even when it did occur, public participation tended to make little or no difference to local governance, there are two significant findings which suggest some reason for hope. First, most respondents were well aware of public participation at least in the sense of having experienced izimbizo - and without exception thought that effective participation would be a good thing. Second, there was some evidence that respondents' perceptions of public participation was positively affected by well-run events, in which there were good follow-ups. This suggests that with the requisite levels of organization and political skill, public participation can be made more meaningful.

Most respondents' experience of engaging with municipal development processes was almost entirely limited to izimbizo, with only a few experiencing ward committees, or any other modality of participation. This reflects the under-developed nature of public participation programmes at municipal level. Research findings also suggested that civil society was very weak in most municipalities, leaving communities without alternative forums to take the initiative with regard to local development.

Some critics might argue that there are existing spaces for engaging with policy processes, as highlighted in discussions with municipal stakeholders, and that civil society needs to be better informed, positioned and active to engage with these. This implies a professional approach to the 
question. A counter to this is that only a privileged few have access to these 'invited spaces', which are not sufficiently advertised or accessible, particularly to marginalized groups. Attempts to facilitate community input are largely superficial and do not tap into the real power-base where decisions are made (Hicks, 2006). In rural municipalities, there were complaints of poorly advertised meetings held at inconvenient times.

Planning in South Africa is a professional process largely conducted by consultants and completed before public engagement. Women, for instance, have a low level of participation in planning, as local government is seen as essentially more conservative than the national government (Todes et al., 2007, p. 122). Consultation generally involves the presentation of pre- Q2 determined positions and programmes for limited feedback or informationsharing only, or creates opportunities for communities to raise concerns only, and therefore makes very little substantive difference.

This thinking is supported by civil society experiences of the policy and planning process, shared in policy discussion forums conducted recently by the CPP and research partner, the South African NGO Coalition Q3 (SANGOCO). Representatives from sectoral civil society groups were invited to share their experiences of participating in the different spheres of government's decision-making processes, and recommendations for making these more accessible and empowering. Groups reflected mixed experiences, with feelings of being sidelined and marginalized, excluded and disempowered overwhelmingly dominating these.

These were occasioned by not receiving feedback on inputs made in processes, not seeing any recommendations being taken up or any impact from having participated and made input, being co-opted into participating in a process with a pre-determined outcome, being excluded from an inner circle' enjoying privileged access to decision-makers and information, and not being recognized as 'worthy' of participating. Concerns were raised at government's tendency to call for community input at advanced stages of policy formulation, for political buy-in and implementation, rather than at the outset when problems and solutions are being developed.

The use of primarily print media in government communication and information dissemination is also considered to exclude certain groups and communities. Representatives from the $\mathrm{CBO}$ discussion group noted Q3 that language used in these processes further alienates communities, and that notice of opportunities to make submissions tend to 'come late', and as a result $\mathrm{CBO}$ are excluded from decision-making. They stated that CBOs need to be involved from the outset of the policy process (Discussion forums, CBO sector, 7/04/05).

These experiences and reflections from civil society stakeholders have told us that although we have legislative provision for participatory 
mechanisms and have many such provisions in place, this is not enabling civil society and local communities to participate meaningfully. Policymakers often acknowledge the limitations of these mechanisms, and civil society experience leaves us in no doubt that these are inadequate, inaccessible and disempowering, and that new approaches to community participation in development planning and policy-making are required. The question is the amplification of practices for engagement and not the displacement of elected representatives. The problem is that the poor and marginalized have the least impact on policy and development planning.

Community stakeholders identified the following specific concerns about existing participation mechanisms and their ability to ensure community involvement in development planning and decision-making:

(1) Community inputs at IDP forums are not adequately integrated into the municipal or district IDPs. Communities felt that these IDPs did not reflect their development priorities.

(2) Ward committee members from a ward dominated by one political party, the Inkatha Freedom Party (IFP), felt that the development priorities they identified were ignored by the dominant political party, the African National Congress (ANC)-aligned district and local municipalities. Political party tensions and competition were perceived as undermining community development and participation.

(3) Effectiveness of izimbizo was perceived in relation to how well organized these were, the follow-up on issues raised, and the extent to which communities concerns are taken seriously.

(4) Ward committees are perceived as lacking real capacity or power to fully assert community needs and input in development planning processes, and engage meaningfully with communities and civil society in this regard.

(5) CDWs are regarded in a positive light in situations where their relationship to the municipality is clearly established. The provision of salaries to CDWs, while ward committee members do not receive any financial support, is an ongoing fundamental source of frustration and resentment in communities, undermining meaningful cooperation between these two structures.

(6) Meetings with councillors are not perceived as having any positive influence on community development processes. Community respondents reported feeling powerless when attempting to interact with their councillors, and that issues raised were not fed into municipal processes adequately. 


\section{Lessons learned}

Participatory processes should lead to greater accountability in political systems; many of the lags in development could be ended with greater responsiveness to the needs of the poor. This would constitute, in short, the 'deepening of democracy' sought in policy formulation processes. At public participation forums, the specific commitments made by government officials should be listed, deadlines accepted, and the tracks of accountability made clear. The notes and minutes taken at public proceedings should be made available to forum participants and published in local newspapers. Community needs expressed at izimbizo should be published along with official responses to key issues.

The popular izimbizo need to be better structured and to serve as a means to achieve greater accountability. These mass meetings at times approach the 'people's assemblies' spoken of by politicians with strong demands for redress and change, but communities complain that change does not follow. Government officials need to do more than take notes as happens at times; they need to make clear and open commitment to make the changes demanded, to accept deadlines and to name those responsible for poor performance and non-delivery. Often the demands expressed Q4 have already been put forward by ward committees; the izimbizo should lead towards establishing effective accountability after the roadshows move on - to align planning, budgeting and implementation and to name those who are accountable.

An alignment between public participation and development planning has to be achieved so that targets and promises for a better life can be achieved. People expect participation to lead to results, and the success of the participatory system is dependent on follow-through after public events. This is only possible in the formal system of planning if plans for delivery and budgets are in place.

Essential information needed for planning, and redress should be made available by municipalities. Promises for change have to be supported by information, for example, on budget allocations for housing, and for housing lists to be available, for community planning to be possible. Too often, even high-level officials are not aware of the prioritization of projects and are thus unable to report on issues directly affecting the poor and to provide the redress spelt out in the Batho Pele principles.

Community-based planning has real potential in the South African context where the poor often put forward demands linked to local communities. These possibilities need to be explored and developed. The problem is not only that the processes are poorly understood; the difficulty is to ensure that the expression of needs and priorities enters the formal 
planning process. The 'professional' and consultancy approach to planning is largely impervious to popular input and greater openness, and inclusivity has to be encouraged.

At the local level, institutional mechanisms need to be modified to ensure that meaningful and contextually appropriate participation takes place. The communities should not be made to endorse pre-determined programmes. There is also a need to work towards a common definition and understanding of public participation including a new and clear policy guideline on public participation, and public participation should be addressed in capacity-building workshops for local government councillors and officials.

The following additional interventions would also be supportive:

(1) There should be a more substantial budget allocated for public participation, and clear guidelines provided to municipalities on staffing requirements and responsibilities for public participation units. These should be established in every municipality.

(2) The convening of IDP forums needs careful consideration so that these are designed in a way to facilitate meaningful contributions from communities to planning processes. Appropriate use should be made of community media to publicize public participation processes, disseminate information and make them more accessible.

(3) A new and common system for performance management needs to be developed, and clear guidelines established for municipalities on how to incorporate communities in the evaluation of municipal stakeholders' performance and service delivery.

(4) Greater clarity is required on the role of ward committees, and appropriate systems developed to address problematic issues encountered. Issues of training of and incentives for ward committee members should also be addressed.

(5) Poor interaction between the district municipality and the local municipality should be addressed. Officials should be accountable, represent the interests of their constituencies and make sure that they report to their constituencies.

(6) A strategy needs to be developed for community-based planning, which will give a clear direction on implementation. Development of guidelines for CDWs would aid in addressing confusion in this area. Greater value should be placed on local knowledge and the approach to development should not be technocratic. 


\section{Conclusion}

Overall the findings of the empirical research on the state of public participation in KZN municipalities are not that positive. The view 'from above' and 'from below' is generally negative. Where officials conceded that public participation mechanism are generally poorly developed, communities affirmed this, adding they felt that they made no difference to local governance and development. Indeed, local communities have experienced little of public participation beyond the izimbizo.

Notably, both officials and communities agree on some of the causes of this malaise: a lack of resources invested in public participation, especially money for staff and training, and the failure to institutionalize public participation effectively in the municipality, and between district and local levels. Lastly, the weakness of civil society means that communities are even more reliant on state good will and effectiveness to realize effective participation in municipal development planning and decision-making.

On the positive side though, there was evidence that respondents' perceptions of public participation was positively affected by well-run events, in which there was good follow-up. This suggests that with the requisite levels of organization and political will, public participation can be made more meaningful. To make the point another way, the solutions to poor public participation appear to comprise: better organization (institutionalization, well-run events), the resources to do this (money, staff, training), and most of all, the political will to make it happen. In this regard, both officials and communities affirmed the value of the idea of public participation - providing something of a basis in political will for improving on the status quo.

Participation is related to the rights of the people and anticipated delivery on community development needs. The level of participation is related to the capacity of the participatory system to provide redress and meet essential needs. Participation is linked to the expectation that the lives of people, the poor, will improve. In a number of cases, the promised improvements and greater accountability of officials were not achieved.

The potential for meaningful, responsive community development through public participation has not yet been realized. There are strong traditions of participation marked by, for example, regular weekly meetings in shack areas and good attendance at izimbizo. Research has found that the heritage of participatory resistance and this current potential is partially reflected in legislation and policy, but not yet developed to reach its potential. The conservative trend in local government tends to lead towards participation being centred around well-established political leadership, rather than building new tiers and drawing on civil society. 
Civil society has yet to find a strategy, which does not lead to incorporation into weak forms of consultation and co-optation of community leadership. The procedures for participation at the municipal level are complex and demand a leadership experienced in expressing community needs, but not vulnerable to co-optation.

In a political system largely dominated by a single political party, public participation opens relief to many who would otherwise find power inaccessible. Participation in development processes encourages a plurality of views, a deepening of democracy as is often advocated, and great possibility for redress by those who have been historically disadvantaged, but these attributes have yet to be realized.

\section{Funding}

Imraan Buccus is Political Researcher at the Centre for Public Participation and a Ph.D. candidate in Development Studies in the Netherlands.

David Hemson is Research Director with the Centre for Service Delivery in the Human Sciences Research Council.

Laurence Piper is Associate Professor, School of Politics, University of KwaZulu-Natal, Pietermaritzburg campus.

Address for correspondence: Janine Hicks is the former Executive Director of the Centre for Public Participation and currently a commissioner with the Commission on Gender Equality; Email: janine@cge.org.za

\section{References}

Constitution of the Republic of South Africa, Act 108 of 1996.

Cornwall, A. (2004) Spaces for transformation? Reflections on issues of power and difference in participation and development, Chapter 5 in Hickey, S. and Mohan, G. eds, Participation: From Tyranny to Transformation, Zed Books, London.

Gaventa, J. (2002) The uses of power in framing and shaping the spaces, places and dynamics of participation, A discussion note for the IDS Citizenship Development Research Centre, 22 October 2002.

Hemson, D. (2007), in Buccus, I. and Hicks, J. eds, Can participation make a difference? Prospects for people's participation in planning. Critical dialogue 3 (1), 9-15.

Hicks, J. (2006), in Buccus, I. and Hicks, J. eds, Assessing the effectiveness of community based involvement, Critical Dialogue 2 (1).

Lahiff, E. and Rugege, S. (2002) A critical assessment of land redistribution policy in the light of the Grootboom judgment. Law Democracy and Development, vol. 6, accessed at: www.communitylawcentre.org.za/Socio-Economic-Rights / 
Page 16 of 16 Imraan Buccus et al.

Sithole, P., Todes, A. and Williamson, A. (2007) Women, decentralisation and Integrated Q6 Development Planning in South Africa Human Sciences Research Council, South Africa. Report to the International Development Research Centre (IDRC), Human Sciences Research Council, Canada.

White Paper on Transforming Public Service Delivery (Batho Pele White Paper) (1997) Republic of South Africa, accessed at: www.info.gov.za/whitepapers/1997/18340.pdf 